\title{
Research on the Stock Correlation Network Entropy and Its Influencing Factors in the Chinese Interbank Market
}

\author{
Qiao Jiang, ${ }^{1}$ Qianting Ma $\mathbb{D}^{2,3}$ and Xiaoxing Liu ${ }^{1,2}$ \\ ${ }^{1}$ School of Cyber Science and Engineering, Southeast University, Nanjing 211189, China \\ ${ }^{2}$ School of Economics and Management, Southeast University, Nanjing 211189, China \\ ${ }^{3}$ College of Finance, Nanjing Agricultural University, Nanjing 210095, China
}

Correspondence should be addressed to Qianting Ma; mqt2626@sina.com

Received 1 April 2021; Revised 28 June 2021; Accepted 19 July 2021; Published 26 July 2021

Academic Editor: Tahir Mahmood

Copyright (c) 2021 Qiao Jiang et al. This is an open access article distributed under the Creative Commons Attribution License, which permits unrestricted use, distribution, and reproduction in any medium, provided the original work is properly cited.

\begin{abstract}
The stability of the interbank market is an essential guarantee for the sustainable development of society. Network entropy theory provides a critical research paradigm for the study of the stability of the interbank market. Considering that few scholars have conducted in-depth analysis on the influencing factors of the network entropy's evolution process, this paper constructs the stock correlation network entropy model in the Chinese interbank market based on the correlation of stock price fluctuation. It focuses on analyzing the influencing factors in the dynamic evolution process of the stock correlation network entropy. In the light of empirical research, we can obtain the following results. First, the interbank market network's aggregation coefficient, the interbank market network's centrality, and the bank stock's return rate play a positive role in the dynamic evolution of stock correlation network entropy in the Chinese interbank market. Second, the bank stock return's volatility is negatively correlated with its network entropy. To maintain the stability of the financial market, the supervision department can monitor the stability of the interbank market by constructing the stock correlation network entropy.
\end{abstract}

\section{Introduction}

The bank is an integral part of the modern financial system and an indispensable financial intermediary for the whole economic system's smooth operation. However, the bank crisis happened frequently. For instance, the Bank of Bahrain collapsed in 1995, which caused strong fluctuation in the financial markets in Asia, Europe, and the Americas. Besides, the vast loss case of Societe Generale in 2008 led to economic shocks throughout Europe and affected global stock markets. Therefore, the study of bank market volatility has attracted some scholars' attention [1-5].

The research on market volatility is mainly to measure the uncertainty of market variables. Veldkamp and Orli [6] pointed out that the main methods to measure the uncertainty of market variables are GARCH (generalized autoregressive conditional heteroskedasticity) model and SV (stochastic volatility) model. The GARCH model is proposed by Bollerslev [7] to describe the volatility clusters of financial asset returns over time. However, the GARCH model only describes the fluctuations related to historical information. Outliers in observations will cause sudden changes in conditional variance, which will affect the stability and longterm forecasting ability of the model. In order to overcome the shortcomings of the GARCH model, Taylor [8] constructs the SV model to make variables independent of past information and then better describe the fat-tail characteristic of financial asset returns. Besides, Shephard [9] and Gysels et al. [10] further summarized and expanded the SV model's statistical features.

Regarding the study of financial market volatility, scholars mainly focus on the stock market. Atkins et al. [11] explored the impact of economic news on the volatility of the U.S. stock market and concluded that volatility movements are more predictable than asset price movements when using financial news as machine learning input. Baker et al. [12] discussed the impact of different policies on the volatility of the U.S. stock market and revealed the monetary policy and 
tax policy as the most critical policy-related sources of stock market volatility. Audrino et al. [13] analyzed the impact of sentiment and attention measures on stock market volatility and showed that the attention and sentiment variables can improve volatility forecasts significantly. However, the magnitudes of the improvements are relatively small from an economic point of view. Notably, recent papers apply forward-looking measures of market volatility using network analysis [14], minimum spanning trees [15], VAR-based connectedness [16], Granger causality [17], and waveletscopula [18]. Besides, Idrees et al. [19], Baek et al. [20], and Liu et al. [21] have also conducted in-depth research on financial market volatility.

In addition to these commonly models, some scholars began to pay attention to the research of financial market volatility from network entropy. The financial market is a complex system full of uncertainty. Network theory is an important method to study the financial system's complexity, which can associate different economic entities. There are a lot of financial network studies, e.g., the correlation-based networks (including MST, PMFG, correlation threshold network, and partial correlation network) and information spillover networks (including mean spillover network, volatility spillover network, and extreme risk spillover network) [22-27]. At the same time, entropy theory has been used to measure uncertainty. Therefore, we integrate network theory and entropy theory to construct network entropy, which can well describe the relevance and volatility of the financial market and then reflect the financial market's stability. The main advantage of network entropy is that it can capture the chaos and uncertainty in a time series without any constraints on the theoretical probability distribution. A lower network entropy means that the network system has a strong stability. For instance, Li et al. [28] have constructed three kinds of network entropy: Shannon network entropy, Renyi network entropy, and Tsallis network entropy. It is found that network entropy can not only be used to describe the fluctuation of the Chinese stock market's return rate but also can be used as a tool for analyzing the structure of stock network. Besides, Pan et al. [29] also constructed Shannon network entropy, Renyi network entropy, and Tsallis network entropy to study stock market volatility and found that Renyi network entropy and Tsallis network entropy have better performance. Besides, Lahmiri et al. [30], Almog and Shmueli [31], and Zalmijn et al. [32] also studied financial market volatility from the perspective of network entropy.

Based on the above studies, it is shown that network entropy can well describe the financial market's volatility. Whether it can also be applied to a specific interbank market remains to be further tested. Moreover, the scholars mentioned above lack the analysis of the influencing factors of network entropy. Considering the shortcomings of the existing research, this paper constructs the stock correlation network entropy model in the Chinese interbank market based on the correlation of stock price fluctuation. It helps us more intuitively understand the correlation and volatility of listed banking institutions and then reflect the whole interbank market's stability. Compared with the existing research, the main contributions of this paper are as follows. First, the stock correlation network entropy is constructed to study the volatility of the Chinese interbank market. Second, the influencing factors in the dynamic evolution process of the Chinese interbank market's stock correlation network entropy are deeply explored. Finally, this paper tests the robustness of the network entropy model.

The remainder of this paper is organized as follows. Section 2 describes the construction of stock correlation network entropy in the Chinese interbank market. In Section 3 , we discuss the main empirical results. Section 4 provides the main conclusion.

\section{Methodology}

Based on the research of Peron et al. [33], Li et al. [28], and Pan et al. [29], it is found that the Renyi network entropy and the Tsallis network entropy perform better than other network entropies in describing stock market volatility. At the same time, the two kinds of network entropy have high robustness. Therefore, this paper constructs the Renyi network entropy and the Tsallis network entropy to study the Chinese interbank market's volatility. In order to construct the stock correlation network entropy model in the Chinese interbank market, we need to build the stock correlation network first. In the bank stock association network, the network node represents a single bank stock, and the network connecting edge represents the correlation of price fluctuation between two bank stocks. There is the price volatility correlation between any two bank stocks, but the correlation strength is different. Therefore, the network is a complete graph. Suppose there are $\mathrm{N}$ bank stocks in the market, and the period is $T$ days. Let $Y_{i}(k)$ be the log-return series of the stock $i$ in the $k$ th window. The correlation coefficient matrix $\rho(k)=\left[\rho_{i j}(k)\right]$, the distance matrix $D(k)=\left[d_{i j}(k)\right]$, and the weight matrix $W(k)=\left[w_{i j}(k)\right]$ in the $k$ th correlation network are shown in the following equations:

$$
\begin{aligned}
& \rho_{i j}(k)=\frac{\left\langle Y_{i}(k) Y_{j}(k)\right\rangle-\left\langle Y_{i}(k)\right\rangle\left\langle Y_{j}(k)\right\rangle}{\sqrt{\left(\left\langle Y_{i}^{2}(k)\right\rangle-\left\langle Y_{i}(k)\right\rangle^{2}\right)\left(\left\langle Y_{j}^{2}(k)\right\rangle-\left\langle Y_{j}(k)\right\rangle^{2}\right)}} \\
& d_{i j}(k)=\sqrt{2\left(1-\rho_{i j}(k)\right)} \\
& w_{i j}(k)=e^{-d_{i j}(k)}
\end{aligned}
$$

where $\left\langle Y_{i}(k)\right\rangle$ represents the mathematical expectation of the sequence $\left\{Y_{i}^{1}(k), Y_{i}^{2}(k), \ldots, Y_{i}^{L}(k)\right\}, \rho_{i j}(k) \in[-1,1]$, $d_{i j}(k) \in[0,2], i=1,2, \ldots, N$, and $j=1,2, \ldots, N$. For the $k$ th stock correlation network, the starting and ending times are $1+(k-1) \delta$ and $(k-1) \delta+L$, respectively, and the total number of stock correlation networks constructed is $\lfloor(T+\delta-L) / \delta\rfloor$.

Furthermore, we need to construct a transition probability matrix in order to construct the stock correlation network entropy of the interbank market. Referring to 


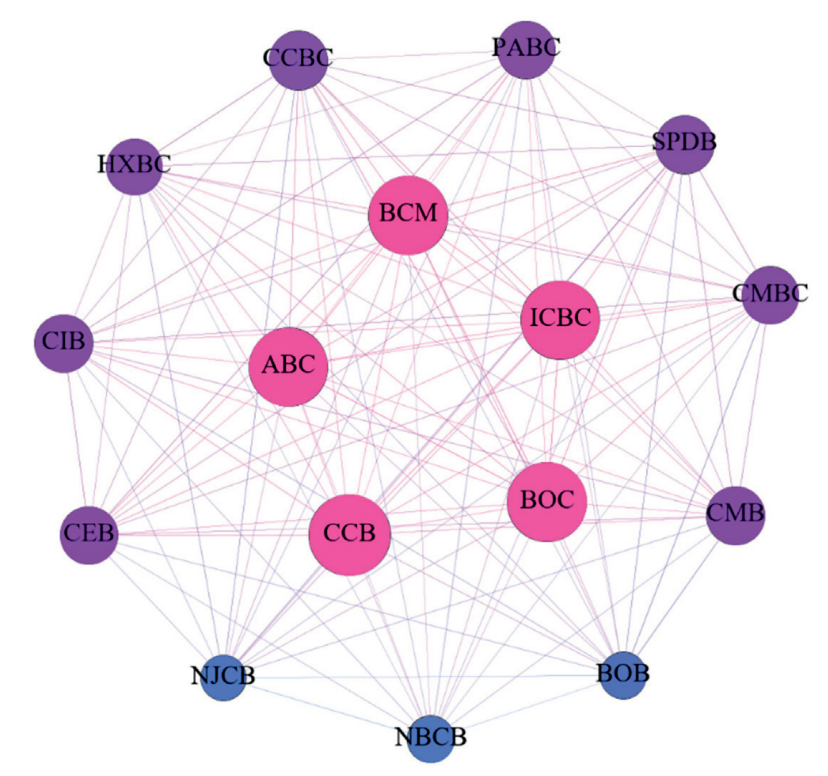

FIGURE 1: The stock correlation network of the Chinese interbank market.

Demetrius et al. [34] and Li et al. [28], for the $k$ th interbank market stock correlation network, the construction method of the transition probability matrix $P(k)=\left[p_{i j}(k)\right]$ is as follows:

$$
p_{i j}(k)=\frac{w_{i j}(k)}{\sum_{j=1}^{N} w_{i j}(k)},
$$

where the transition probability $p_{i j}(k)$ between bank stock $i$ and bank stock $j$ satisfies $p_{i j}(k) \geq 0$ and $\sum_{j=1}^{N} p_{i j}(k)=1$.

According to the formulas of Renyi and Tsallis entropies $[35,36]$, the Renyi entropyHR $R_{i}(k)$ and the Tsallis entropy $H T_{i}(k)$ of bank stock $i$ of the $k$ th stock correlation network can be calculated as follows:

$$
\begin{aligned}
& H R_{i}(k)=\frac{1}{1-\beta} \log \left(\sum_{j=1}^{N} p_{i j}^{\beta}(k)\right), \\
& H T_{i}(k)=\frac{1}{\beta-1}\left(1-\sum_{j=1}^{N} p_{i j}^{\beta}(k)\right),
\end{aligned}
$$

where the parameter $\beta$ is used to adjust the gravity center of the frequency distributions of log-returns in the Renyi entropies $H R_{i}(k)$ and the Tsallis entropies $H T_{i}(k)$.

Based on the above analysis, the Renyi network entropy $H R(k)$ and the Tsallis network entropy $H T(k)$ of the kth stock correlation network can be calculated as follows:

$$
\begin{aligned}
& H R(k)=\sum_{i=1}^{N} \omega_{i}(k) H R_{i}(k), \\
& H T(k)=\sum_{i=1}^{N} \omega_{i}(k) H T_{i}(k),
\end{aligned}
$$

where $\omega_{i}(k)$ is the $k$ th component of the unique invariant distribution of the corresponding transfer probability matrix $P(k)=\left[p_{i j}(k)\right]$, satisfying $\omega=\omega P$.

\section{Empirical Analysis}

3.1. Data. We initially selected 37 banking stocks based on the Wind database. Further, we screened out 16 stocks that have been suspended for not more than 30 consecutive trading days and whose daily log-return is not zero for 30 consecutive trading days. Therefore, we collect 16 stocks of Chinese listed banks in 2432 trading days from January 1, 2011, to December 31, 2020. The daily closing price data of all stocks are processed by forwarding weighting. After the initial data processing, we can get the daily log-return data of 16 stocks for a total of 2431 trading days. In this paper, let the time window $L$ be 1 month, the network interval $\delta$ be 1 month, and the total stock correlation networks be 120. Figure 1 depicts the 120th stock correlation network of the Chinese interbank market. According to the Wind database's bank classification standard, we divide the 16 stocks into three categories: large state-owned banks, national joint-stock banks, and regional banks. Among them, large state-owned banks include "ABC," "BCM," "ICBC," "CCB," and "BOC," national joint-stock banks include "PABC," “SPDB," "HXBC," "CMBC," “CMB," "CIB," "CEB," and "CCBC," and regional banks include "NBCB," "NJCB," and "BOB." The basic information of these 16 stocks is shown in Table 1 in Appendix, including the stock abbreviation, the stock full name, and the stock code.

3.2. Dynamic Evolution of Network Entropy. Figures 2 and 3 display the dynamic evolution of the Renyi network entropy and the Tsallis network entropy from January 2011 to December 2020, respectively. Referring to the research of $\mathrm{Li}$ et al. [28], the adjustment parameters of the Renyi network entropy and the Tsallis network entropy are $0.1,0.5$, and 2.5 , respectively. According to the descriptive statistics in Figure 2 and Table 2, the corresponding Renyi network entropy decreases slightly with the increase in the adjusting parameter value. In the whole evolution process, the Renyi network entropy with different adjustment parameters fluctuates steadily in their respective intervals (2.764, 2.772), (2.723, 2.769), and (2.402, 2.754), respectively. Further, according to the descriptive statistics in Figure 3 and Table 2, the Tsallis network entropy decreases significantly with the increase in the adjusting parameter value. In the whole evolution process, the Tsallis network entropy with different adjustment parameters fluctuates steadily in their respective intervals $(12.253,12.353)$, $(5.805,5.986)$, and $(0.649,0.656)$, respectively. The above research demonstrates that the Chinese banking industry shows good stability in the stock market. According to Figure 2 and Figure 3, we also discover that the Renyi network entropy and the Tsallis network entropy show a certain degree of fluctuation similarity under different adjustment parameters. In addition, according to the correlation statistics in Table 3, the similarity of network entropies is very high under different adjustment parameters. The internal factors of network entropy need further quantitative research. 
TABLE 1: Stock information of Chinese interbank market.

\begin{tabular}{lcc}
\hline Stock abbreviation & Stock full name & Stock code \\
\hline ABC & Agricultural Bank of China Limited & 601288 \\
BCM & Bank of Communications Co. Ltd & 601328 \\
ICBC & Industrial and Commercial Bank of China Limited & 601398 \\
CCB & China Construction Bank Corporation & 601939 \\
BOC & Bank of China limited \\
PABC & Ping an Bank Co. Ltd. \\
SPDB & Shanghai Pudong Development Bank Co. Ltd \\
HXBC & Hua xia Bank Co. Ltd. \\
CMBC & China Minsheng Banking Corp. Ltd \\
CMB & China Merchants Bank Co. Ltd \\
CIB & Industrial Bank Co. Ltd \\
CEB & China Everbright Bank Co. Ltd \\
CCBC & China Citic Bank Corporation Limited \\
NBCB & Bank of Ningbo Co. Ltd \\
NJCB & Bank of Nanjing Co. Ltd \\
BOB & Bank of Beijing Co. Ltd \\
\hline
\end{tabular}
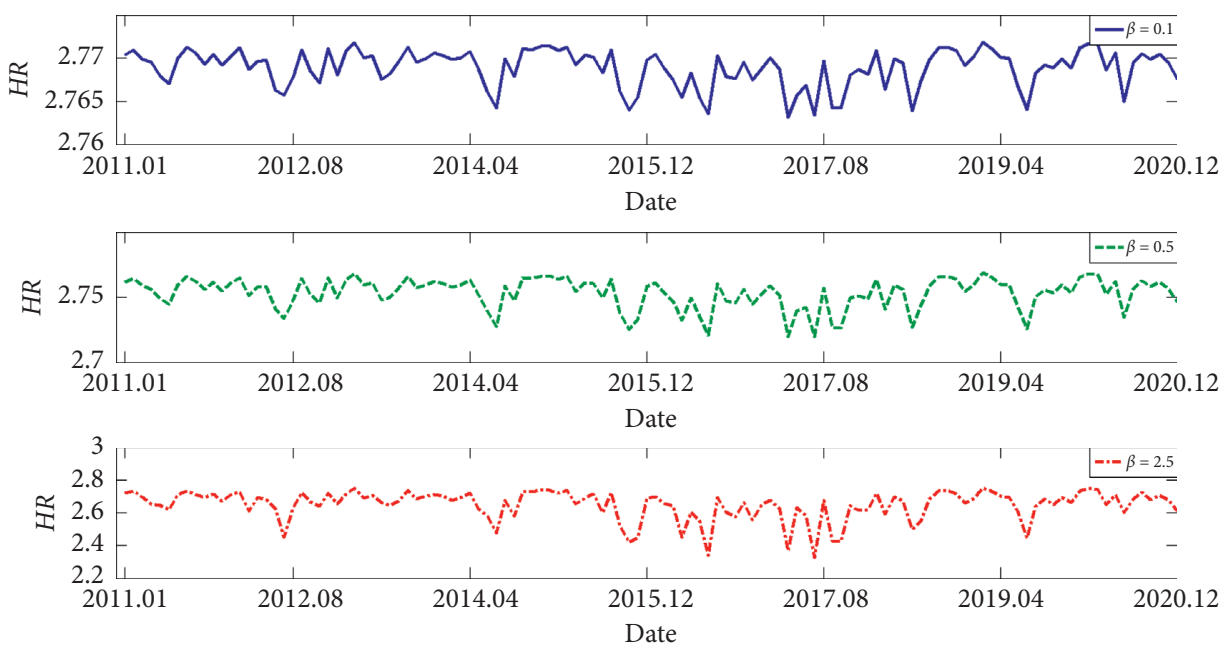

FIGURE 2: Evolution of the Renyi network entropy.
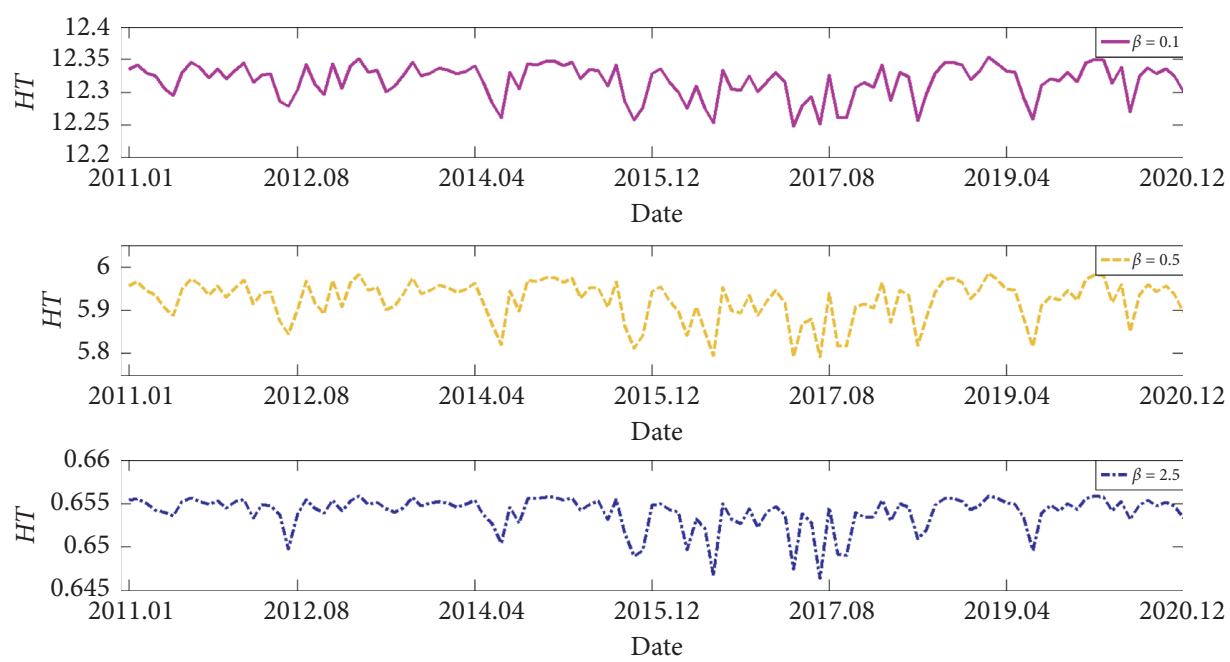

FIgURE 3: Evolution of the Tsallis network entropy. 
TABLE 2: Descriptive statistics of the network entropy.

\begin{tabular}{lcccc}
\hline Variable & Mean & Sd & Min & Max \\
\hline$H R(\beta=0.1)$ & 2.769 & 0.002 & 2.764 & 2.772 \\
$H R(\beta=0.5)$ & 2.754 & 0.010 & 2.723 & 2.769 \\
$H R(\beta=2.5)$ & 2.659 & 0.071 & 2.402 & 2.754 \\
$H T(\beta=0.1)$ & 12.320 & 0.022 & 12.253 & 12.353 \\
$H T(\beta=0.5)$ & 5.928 & 0.039 & 5.805 & 5.986 \\
$H T(\beta=2.5)$ & 0.654 & 0.001 & 0.649 & 0.656 \\
\hline
\end{tabular}

3.3. Influencing Factors of Network Entropy. The network aggregation coefficient and the network centrality are important topological indexes to describe the stock correlation network in the interbank market (Pan et al. [29]). The bank stock return rate, the bank stock return's volatility, the bank size, and the bank age are important indicators to reflect the financial and operational status of banks (Milanov and Shepherd [37]; Pollock et al. [38]). Therefore, to further explore the factors that affect the stock correlation network entropy of the Chinese interbank market in the dynamic evolution process, this paper takes the interbank market network's aggregation coefficient, the interbank market network's centrality, the bank stock return rate, the bank stock return's volatility, the bank size, and the bank age into the research model. Based on the previous research ideas, we construct the research model as follows:

$$
H=\alpha_{0}+\alpha_{1} C+\alpha_{2} D+\alpha_{3} \text { Roa }+\alpha_{4} R V+\alpha_{5} \text { Size }+\alpha_{6} \text { Age }+\varepsilon,
$$

where $H$ represents the interbank stock market's network entropy, measured by the Renyi network entropy $(H R)$ and the Tsallis network entropy $(H T)$. C stands for the aggregation coefficient of nodes in the interbank market network, calculated by the aggregation coefficient formula in the undirected weighted network [39]. D denotes the degree centrality of nodes in the interbank market network, adopted by the calculation formula of degree centrality in the undirected weighted network [40]. Roa represents the bank stock return rate, indicating the average monthly return of bank stock. RV stands for the bank stock return's volatility, representing the volatility of monthly bank stock return. Size denotes the bank scale, which means the natural logarithm of the bank's market value. Age stands for the bank age, indicating the number of years from the bank's listing to the current year and taking the logarithm. The above research data are obtained from the Wind database. Besides, to control extreme values' influence, we winsorize all continuous variables according to the standard of $1 \%$.

Table 4 reports the regression results of the factors affecting the network entropy in the Chinese interbank market when the adjustment parameters of the Renyi network entropy and the Tsallis network entropy are both 2.5. This paper uses both random effects (RE) and fixed effects (FE) in terms of model selection. Columns (1) and (3) report the estimation results of random effects, and columns (2) and (4) report the estimation results of fixed effects. Although both random effects and fixed effects are used in this paper, compared with the random-effect model, the fixed-effect model can better solve the problem of omitted variable bias caused by the lack of control over those problematic to observe individual characteristics. Moreover, Hausman tests reject the null hypothesis that personal effects are not related to explanatory variables. Therefore, this paper mainly discusses the regression results under the fixed-effect model.

From the regression results of the fixed-effect model, we can see that the regression coefficients of $C$ and $D$ are significantly positive. It indicates that the aggregation coefficient and the interbank market network's centrality play a positive role in the dynamic evolution of stock correlation network entropy in the Chinese interbank market. This also reflects that the Renyi network entropy and the Tsallis network entropy can describe the changing direction of the Chinese interbank market network structure. Besides, the regression coefficients of Roa and Size are also significantly positive, which indicates that bank stock return and bank size play a positive role in the dynamic evolution process of stock correlation network entropy. It reveals that banks' income and scale play a significant role in the interbank market's stability. Furthermore, the regression coefficient of $\mathrm{RV}$ is significantly negative, which indicates that the bank stock return's volatility is negatively correlated with the stock correlation network entropy in the interbank market. It also brings to light that the more extensive market volatility will hinder the interbank market's stability. In addition, the regression coefficient of age is significantly negative, which indicates that the bank age is negatively correlated with their network entropy. It means that the senior banks are at the core of the interbank market network, and once they have large fluctuations, they will more easily affect the stability of the interbank market.

3.4. Robustness. In this paper, the research conclusion's robustness test is divided into two parts: one is the grouping test according to the bank nature; the other is the robustness test by adjusting the network entropy parameters. According to the bank classification standard of the Wind database, we divide 16 stocks into three categories: state-owned large banks, national joint-stock banks, and regional banks. We discuss the group regression results under the fixed-effect model. According to Table 5, we can find that the regression coefficients of $\mathrm{C}$ and $\mathrm{D}$ are significantly positive under different grouping conditions, which shows that the Renyi network entropy and the Tsallis network entropy can well describe the changing direction of interbank market network structure under different bank nature groups. Simultaneously, the regression coefficient of Roa is also positive, which indicates that both the Renyi network entropy and the Tsallis network entropy can reflect the bank income well in the Chinese interbank market. Furthermore, the regression coefficient of RV is significantly negative, which shows that both the Renyi network entropy and the Tsallis network entropy can well reflect the volatility of the interbank market under different bank nature groups. In addition, we also discover that the regression coefficient of size under the classification of large state-owned banks is not significant, which to a certain extent shows that large state- 
TABLE 3: The correlations between the network entropies.

\begin{tabular}{|c|c|c|c|c|c|c|}
\hline- & $H R(\beta=0.1)$ & $H R(\beta=0.5)$ & $H R(\beta=2.5)$ & $H T(\beta=0.1)$ & $H T(\beta=0.1)$ & $H T(\beta=2.5)$ \\
\hline$H R(\beta=0.1)$ & 1 & & & & & \\
\hline$H R(\beta=0.5)$ & 0.9968 & 1 & & & & \\
\hline$H R(\beta=2.5)$ & 0.9391 & 0.9634 & 1 & & & \\
\hline$H T(\beta=0.1)$ & 0.9999 & 0.9967 & 0.9389 & 1 & & \\
\hline$H T(\beta=0.5)$ & 0.9969 & 0.9999 & 0.9630 & 0.9969 & 1 & \\
\hline$H T(\beta=2.5)$ & 0.9188 & 0.9470 & 0.9960 & 0.9186 & 0.9463 & 1 \\
\hline
\end{tabular}

TABLE 4: The regression results of the factors affecting the network entropy.

\begin{tabular}{|c|c|c|c|c|}
\hline \multirow[b]{2}{*}{ Variables } & \multicolumn{2}{|c|}{$H R(\beta=2.5)$} & \multicolumn{2}{|c|}{$H T(\beta=2.5)$} \\
\hline & $\begin{array}{l}\mathrm{RE} \\
(1)\end{array}$ & $\begin{array}{l}\mathrm{FE} \\
(2)\end{array}$ & $\begin{array}{l}\mathrm{RE} \\
(3)\end{array}$ & $\begin{array}{l}\mathrm{FE} \\
(4)\end{array}$ \\
\hline $\mathrm{C}$ & $\begin{array}{c}0.153^{* * * *} \\
(14.88)\end{array}$ & $\begin{array}{c}0.149^{* * *} \\
(14.73)\end{array}$ & $\begin{array}{c}0.003^{* * *} \\
(10.68)\end{array}$ & $\begin{array}{c}0.003^{* * *} \\
(10.82)\end{array}$ \\
\hline $\mathrm{D}$ & $\begin{array}{c}0.651^{* * *} \\
(62.63)\end{array}$ & $\begin{array}{c}0.655^{* * *} \\
(64.42)\end{array}$ & $\begin{array}{c}0.013^{* * *} \\
(45.82)\end{array}$ & $\begin{array}{c}0.013^{* * *} \\
(48.03)\end{array}$ \\
\hline Roa & $\begin{array}{c}0.747^{* * *} \\
(7.59)\end{array}$ & $\begin{array}{c}0.612^{* * *} \\
(6.18)\end{array}$ & $\begin{array}{c}0.019^{* * *} \\
(7.79)\end{array}$ & $\begin{array}{c}0.015^{* * *} \\
(6.40)\end{array}$ \\
\hline RV & $\begin{array}{c}-0.151^{* * *} \\
(-9.76)\end{array}$ & $\begin{array}{c}-0.177^{* * *} \\
(-11.45)\end{array}$ & $\begin{array}{c}-0.004^{* * *} \\
(-10.15)\end{array}$ & $\begin{array}{c}-0.005^{* * *} \\
(-12.05)\end{array}$ \\
\hline Size & $\begin{array}{c}0.001^{*} \\
(1.65)\end{array}$ & $\begin{array}{c}0.007^{* * *} \\
(3.67)\end{array}$ & $\begin{array}{l}0.000 \\
(1.50)\end{array}$ & $\begin{array}{c}0.000^{* * *} \\
(4.31)\end{array}$ \\
\hline Age & $\begin{array}{l}-0.000 \\
(-0.36)\end{array}$ & $\begin{array}{c}-0.004^{* *} \\
(-2.14)\end{array}$ & $\begin{array}{l}-0.000 \\
(-0.55)\end{array}$ & $\begin{array}{c}-0.000^{* *} \\
(-2.65)\end{array}$ \\
\hline Constant & $\begin{array}{c}0.584^{* * *} \\
(20.66)\end{array}$ & $\begin{array}{c}0.446^{* * *} \\
(12.03)\end{array}$ & $\begin{array}{c}0.613^{* * * *} \\
(7.86)\end{array}$ & $\begin{array}{c}0.609^{* * *} \\
(6.89)\end{array}$ \\
\hline Observations & 1,920 & 1,920 & 1,920 & 1,920 \\
\hline R-squared & 0.868 & 0.226 & 0.801 & 0.088 \\
\hline $\begin{array}{l}\text { Hausman test } \\
\text { Chi-square }\end{array}$ & \multicolumn{2}{|c|}{$\begin{array}{c}P<0.0001 \\
264.51\end{array}$} & \multicolumn{2}{|c|}{$\begin{array}{c}P=0.0491 \\
12.43\end{array}$} \\
\hline
\end{tabular}

Note. FE and RE represent fixed-effect and random-effect estimations, respectively. Chi-square refers to the Hausman test values. ${ }^{*}$ denotes significance at the $10 \%$ level; ${ }^{* *}$ denotes significance at the $5 \%$ level; ${ }^{* * *}$ denotes significance at the $1 \%$ level; T-statistics are reported in parentheses under the estimated coefficient and are based on robust standard errors.

TABLE 5: Grouping test results according to the bank nature.

\begin{tabular}{|c|c|c|c|c|c|c|}
\hline \multirow{3}{*}{ Variables } & \multicolumn{6}{|c|}{$\mathrm{FE}$} \\
\hline & \multicolumn{2}{|c|}{ Large state-owned banks } & \multicolumn{2}{|c|}{ National joint-stock banks } & \multicolumn{2}{|c|}{ Regional banks } \\
\hline & $\begin{array}{c}H R \\
(1)\end{array}$ & $\begin{array}{l}H T \\
(2)\end{array}$ & $\begin{array}{l}H R \\
\text { (3) }\end{array}$ & $\begin{array}{l}H T \\
(4)\end{array}$ & $\begin{array}{l}H R \\
(5)\end{array}$ & $\begin{array}{l}H T \\
(6)\end{array}$ \\
\hline $\mathrm{C}$ & $\begin{array}{c}0.151^{* * *} \\
(11.37)\end{array}$ & $\begin{array}{c}0.003^{* * * *} \\
(8.17)\end{array}$ & $\begin{array}{c}0.141^{* * *} \\
(7.52)\end{array}$ & $\begin{array}{c}0.002^{* * *} \\
(5.49)\end{array}$ & $\begin{array}{c}0.121^{* *} \\
(5.89)\end{array}$ & $\begin{array}{l}0.002^{*} \\
(4.23)\end{array}$ \\
\hline $\mathrm{D}$ & $\begin{array}{c}0.672^{* * * *} \\
(29.33)\end{array}$ & $\begin{array}{c}0.014^{* * *} \\
(23.64)\end{array}$ & $\begin{array}{c}0.645^{* * *} \\
(36.87)\end{array}$ & $\begin{array}{c}0.013^{* * *} \\
(28.23)\end{array}$ & $\begin{array}{c}0.697^{* * * *} \\
(85.20)\end{array}$ & $\begin{array}{c}0.014^{* * *} \\
(40.74)\end{array}$ \\
\hline Roa & $\begin{array}{c}0.784^{* * *} \\
(5.70)\end{array}$ & $\begin{array}{c}0.020^{* * * *} \\
(6.81)\end{array}$ & $\begin{array}{c}0.523^{* *} \\
(3.46)\end{array}$ & $\begin{array}{c}0.013^{* *} \\
(3.40)\end{array}$ & $\begin{array}{c}0.617^{* * * *} \\
(22.80)\end{array}$ & $\begin{array}{c}0.015^{* * *} \\
(11.13)\end{array}$ \\
\hline RV & $\begin{array}{c}-0.220^{* * *} \\
(-5.01)\end{array}$ & $\begin{array}{c}-0.005^{* * *} \\
(-5.23)\end{array}$ & $\begin{array}{c}-0.155^{* * *} \\
(-7.72)\end{array}$ & $\begin{array}{c}-0.004^{* * *} \\
(-7.61)\end{array}$ & $\begin{array}{c}-0.182^{* *} \\
(-9.74)\end{array}$ & $\begin{array}{c}-0.005^{* * *} \\
(-10.64)\end{array}$ \\
\hline Size & $\begin{array}{l}0.004 \\
(0.52)\end{array}$ & $\begin{array}{l}0.000 \\
(0.62)\end{array}$ & $\begin{array}{c}0.006^{* *} \\
(2.99)\end{array}$ & $\begin{array}{c}0.000^{* * *} \\
(3.11)\end{array}$ & $\begin{array}{c}0.012^{* * *} \\
(16.15)\end{array}$ & $\begin{array}{c}0.000^{* * *} \\
(15.54)\end{array}$ \\
\hline Age & $\begin{array}{c}-0.011^{* *} \\
(-3.49)\end{array}$ & $\begin{array}{c}-0.000^{* *} \\
(-3.21)\end{array}$ & $\begin{array}{l}-0.001 \\
(-0.61)\end{array}$ & $\begin{array}{l}-0.000 \\
(-1.13)\end{array}$ & $\begin{array}{l}0.006 \\
(2.02)\end{array}$ & $\begin{array}{l}0.000 \\
(1.61)\end{array}$ \\
\hline Constant & $\begin{array}{c}0.445^{* *} \\
(3.24)\end{array}$ & $\begin{array}{c}0.609^{* * * *} \\
(20.84)\end{array}$ & $\begin{array}{c}0.494^{* * *} \\
(11.40)\end{array}$ & $\begin{array}{c}0.611^{* * * *} \\
(58.63)\end{array}$ & $\begin{array}{c}0.237^{* *} \\
(5.75)\end{array}$ & $\begin{array}{c}0.604^{* * *} \\
(42.87)\end{array}$ \\
\hline Observations & 600 & 600 & 960 & 960 & 360 & 360 \\
\hline R-squared & 0.570 & 0.183 & 0.781 & 0.685 & 0.059 & 0.008 \\
\hline
\end{tabular}

Note. This table presents results obtained from FE regressions. ${ }^{*}$ denotes significance at the $10 \%$ level; ${ }^{* *}$ denotes significance at the $5 \%$ level; ${ }^{* * *}$ denotes significance at the $1 \%$ level; $\mathrm{T}$-statistics are reported in parentheses under the estimated coefficient and are based on robust standard errors. 
TABLE 6: Robustness test by adjusting the network entropy parameters.

\begin{tabular}{lcccc}
\hline & $H R$ & $H R$ & $H T$ & $H T$ \\
Variables & $(\beta=0.1)$ & $(\beta=0.5)$ & $(\beta=0.1)$ & $(\beta=0.5)$ \\
& $\mathrm{FE}$ & $\mathrm{FE}$ & $\mathrm{FE}$ & $\mathrm{FE}$ \\
& $(1)$ & $(2)$ & $(3)$ & $(4)$ \\
\hline $\mathrm{C}$ & $0.011^{* * *}$ & $0.053^{* * *}$ & $0.135^{* * *}$ & $0.209^{* * *}$ \\
& $(21.59)$ & $(21.16)$ & $(21.61)$ & $(21.23)$ \\
$\mathrm{D}$ & $0.011^{* * *}$ & $0.068^{* * *}$ & $0.137^{* * *}$ & $0.268^{* * *}$ \\
& $(34.07)$ & $(40.71)$ & $(34.12)$ & $(40.93)$ \\
Roa & $0.009^{*}$ & $0.058^{* *}$ & $0.113^{*}$ & $0.229^{* *}$ \\
& $(2.09)$ & $(2.75)$ & $(2.09)$ & $(2.73)$ \\
RV & $-0.003^{* * *}$ & $-0.017^{* * *}$ & $-0.031^{* * *}$ & $-0.065^{* * *}$ \\
& $(-4.74)$ & $(-5.88)$ & $(-4.72)$ & $(-5.82)$ \\
Size & 0.000 & 0.001 & 0.001 & 0.003 \\
& $(1.00)$ & $(1.38)$ & $(1.00)$ & $(1.36)$ \\
Age & -0.000 & -0.000 & -0.000 & -0.001 \\
& $(-0.10)$ & $(-0.38)$ & $(-0.09)$ & $(-0.36)$ \\
Constant & $2.725^{* * *}$ & $2.501^{* * *}$ & $11.790^{* * *}$ & $4.926^{* * *}$ \\
Observations & $(12.80)$ & $(24.94)$ & $(4.58)$ & $(12.42)$ \\
R-squared & 1,920 & 1,920 & 1,920 & 1,920 \\
Hausman & 0.226 & 0.192 & 0.229 & 0.202 \\
test & $P=0.0085$ & $P=0.0002$ & $P=0.0089$ & $P=0.0003$ \\
Chi-square & 17.23 & 25.80 & 17.12 & 25.35 \\
\hline
\end{tabular}

Note. ${ }^{*},{ }^{* *}$, and ${ }^{* * *}$ indicate $10 \%, 5 \%$, and $1 \%$ significant, respectively; Tstatistics are reported in the parentheses.

owned banks have the government endorsement and will not fail, which has high stability. Besides, there are significant differences in the regression coefficient of age under different bank nature groups, which also discovers that the bank age's influence on the network entropy evolution under different bank nature groups is weak.

Next, we adjust the network entropy parameters to test the model robustness. Table 6 mainly reflects the regression results of the Renyi network entropy and the Tsallis network entropy under the fixed-effect model, in which the adjustment parameters are 0.1 and 0.5 , respectively. The results demonstrate that the regression coefficients of $C, D$, Roa, and $R V$ are significant, revealing that the Renyi network entropy and the Tsallis network entropy have good robustness in describing the network structure and volatility of the interbank market and reflecting the bank income under different adjustment parameters. Besides, the regression coefficients of size and age are not significant, which indicates that the Renyi network entropy and the Tsallis network entropy perform better when the adjustment parameter is 2.5 as shown in Table 3, which is consistent with the research conclusion of Pan et al. [18].

\section{Conclusions}

The bank is an integral part of the modern financial system. The stability of the interbank market is an essential guarantee for the sustainable development of society. Based on this, we collect 16 stocks in the Chinese interbank market and then construct the stock correlation network entropy model. By analyzing the correlation and volatility of listed banking institutions, the whole interbank market's stability can be reflected. This paper focuses on analyzing the influencing factors in the dynamic evolution process of the stock correlation network entropy and tests the robustness of the network entropy model.

In the light of empirical research, we can obtain the following results. First, the stock correlation network entropy in the Chinese interbank market fluctuates steadily in the process of dynamic evolution, which indicates that the Chinese banking industry shows good stability in the stock market. Second, the Renyi network entropy and the Tsallis network entropy can well describe the changing direction of the Chinese interbank market network structure. Thirdly, the Renyi network entropy and the Tsallis network entropy can well reflect the volatility of the interbank market. Finally, when the adjustment parameter is 2.5 , the Renyi network entropy and the Tsallis network entropy models are more robust.

According to the above research results, we can draw the following enlightenments. The network entropy theory provides a vital research paradigm for the study of the stability of the interbank market. The Renyi network entropy and the Tsallis network entropy can be used as early warning indicators to measure the stability of the interbank market. It is helpful for policy makers to understand the interbank market's volatility more objectively by constructing the stock correlation network entropy, which has a specific practical significance for strengthening the risk monitoring and maintaining the smooth operation of the interbank market. Simultaneously, it also plays a warning role for investment institutions to avoid risks.

\section{Data Availability}

The data used to support the findings of the study are obtained from the Wind database.

\section{Conflicts of Interest}

The authors declare that there are no conflicts of interest.

\section{Acknowledgments}

This research was supported by NSFC (no. 71673043).

\section{References}

[1] S. Papadamou, M. Sidiropoulos, and E. Spyromitros, "Does central bank independence affect stock market volatility?" Research in International Business and Finance, vol. 42, pp. 855-864, 2017.

[2] A. A. Khan and A. Zia, "Market volatility of banking stock return vis-à-vis banks merger: an application of GARCH model," Management Science Letters, vol. 9, no. 5, pp. 629-638, 2019.

[3] C. Liu, "Organization evolution of fuzzy system based on financial risk degree of commercial banks," Mathematical Problems in Engineering, vol. 2021, Article ID 6698299, 8 pages, 2021.

[4] M. Ehrmann and J. Talmi, "Starting from a blank page? Semantic similarity in central bank communication and market 
volatility," Journal of Monetary Economics, vol. 111, pp. 48-62, 2020.

[5] Y. M. Du, J. F. Chen, X. Guan, and C. P Sun, "Maximum entropy approach to reliability of multi-component systems with non-repairable or repairable components," Entropy (Basel, Switzerland), vol. 23, no. 3, Article ID 348, 2021.

[6] L. Veldkamp and A. Orlik, Understanding Uncertainty Shocks and the Role of the Black Swan, New York University, Leonard N. Stern School of Business, Department of Economics, New York, NY, USA, 2016.

[7] T. Bollerslev, "Generalized autoregressive conditional heteroskedasticity," Journal of Econometrics, vol. 31, no. 3, pp. 307-327, 1986.

[8] S. J. Taylor, "Modeling stochastic volatility: a review and comparative study," Mathematical Finance, vol. 4, no. 2, pp. 183-204, 1994.

[9] N. Shephard, "Statistical aspects of $\mathrm{ARCH}$ and stochastic volatility," Time Series Models, vol. 65, pp. 1-67, 1996.

[10] E. Ghysels, A. C. Harvey, and E. Renault, "5 Stochastic volatility," Handbook of Statistics, vol. 14, pp. 119-191, 1996.

[11] A. Atkins, M. Niranjan, and E. Gerding, "Financial news predicts stock market volatility better than close price," The Journal of Finance and Data Science, vol. 4, no. 2, pp. 120-137, 2018.

[12] S. Baker, N. Bloom, S. Davis, and K. Kost, Policy News and Stock Market Volatility, National Bureau of Economic Research, Cambridge, MA, USA, 2019.

[13] F. Audrino, F. Sigrist, and D. Ballinari, "The impact of sentiment and attention measures on stock market volatility," International Journal of Forecasting, vol. 36, no. 2, pp. 334357, 2020.

[14] Q. Ji, E. Bouri, and D. Roubaud, "Dynamic network of implied volatility transmission among US equities, strategic commodities, and BRICS equities," International Review of Financial Analysis, vol. 57, pp. 1-12, 2018.

[15] E. Bouri, D. Roubaud, R. Jammazi, and A. Assaf, "Uncovering frequency domain causality between gold and the stock markets of China and India: evidence from implied volatility indices," Finance Research Letters, vol. 23, pp. 23-30, 2017.

[16] A. Dutta, E. Bouri, and T. Saeed, "News-based equity market uncertainty and crude oil volatility," Energy, vol. 222, Article ID 119930, 2021.

[17] E. Bouri, B. Lucey, T. Saeed, and X. V. Vo, "The realized volatility of commodity futures: interconnectedness and determinants," International Review of Economics \& Finance, vol. 73, pp. 139-151, 2021.

[18] W. Mensi, A. Tiwari, E. Bouri, D. Roubaud, and K. H. AlYahyaee, "The dependence structure across oil, wheat, and corn: a wavelet-based copula approach using implied volatility indexes," Energy Economics, vol. 66, pp. 122-139, 2017.

[19] S. M. Idrees, M. A. Alam, and P. Agarwal, "A prediction approach for stock market volatility based on time series data," IEEE Access, vol. 7, pp. 17287-17298, 2019.

[20] S. Baek, S. K. Mohanty, and M. Glambosky, "COVID-19 and stock market volatility: an industry level analysis," Finance Research Letters, vol. 37, Article ID 101748, 2020.

[21] L. Liu, F. Ma, Q. Zeng, and Y. Zhang, "Forecasting the aggregate stock market volatility in a data-rich world," Applied Economics, vol. 52, no. 32, pp. 3448-3463, 2020.

[22] J. Birch, A. A. Pantelous, and K. Soramäki, "Analysis of correlation based networks representing DAX 30 stock price returns," Computational Economics, vol. 47, no. 4, pp. 501-525, 2016.
[23] C.-X. Nie and F.-T. Song, "Constructing financial network based onPMFGand threshold method," Physica A: Statistical Mechanics and Its Applications, vol. 495, pp. 104-113, 2018.

[24] O. Shirokikh, G. Pastukhov, V. Boginski et al., "Computational study of the US stock market evolution: a rank correlation-based network model," Computational Management Science, vol. 10, no. 2-3, pp. 81-103, 2013.

[25] G.-J. Wang, C. Xie, and H. E. Stanley, "Correlation structure and evolution of world stock markets: evidence from Pearson and partial correlation-based networks," Computational Economics, vol. 51, no. 3, pp. 607-635, 2018.

[26] G.-J. Wang, C. Xie, K. He, and H. E. Stanley, "Extreme risk spillover network: application to financial institutions," Quantitative Finance, vol. 17, no. 9, pp. 1417-1433, 2017.

[27] X. Liu, H. An, H. Li, Z. Chen, S. Feng, and S. Wen, "Features of spillover networks in international financial markets: evidence from the G20 countries," Physica A: Statistical Mechanics and Its Applications, vol. 479, pp. 265-278, 2017.

[28] S. Li, J. He, and K. Song, "Network entropies of the Chinese financial market," Entropy, vol. 18, no. 9, Article ID 331, 2016.

[29] Z. Pan, Q. Ma, J. Ding et al., "Research on the stock correlation networks and network entropies in the Chinese green financial market," The European Physical Journal B, vol. 94, no. 2, pp. 1-11, 2021.

[30] S. Lahmiri and S. Bekiros, "Disturbances and complexity in volatility time series," Chaos, Solitons \& Fractals, vol. 105, pp. 38-42, 2017.

[31] A. Almog and E. Shmueli, "Structural entropy: monitoring correlation-based networks over time with application to financial markets," Scientific Reports, vol. 9, no. 1, pp. 10832-10913, 2019.

[32] E. Zalmijn, T. Heskes, and T. Claassen, "Spectral ranking of causal influence in complex systems," Entropy (Basel, Switzerland), vol. 23, no. 3, Article ID 369, 2021.

[33] T. Peron, L. Costa, and F. A. Rodrigues, "The structure and resilience of financial market networks," Chaos: An Interdisciplinary Journal of Nonlinear Science, vol. 22, no. 1, Article ID 013117, 2012.

[34] L. Demetrius and T. Manke, "Robustness and network evolution-an entropic principle," Physica A: Statistical Mechanics and Its Applications, vol. 346, no. 3, pp. 682-696, 2005.

[35] A. Renyi, Probability Theory, Dover, New York, NY, USA, 1970.

[36] C. Tsallis, R. Mendes, and A. R. Plastino, "The role of constraints within generalized nonextensive statistics," Physica A: Statistical Mechanics and Its Applications, vol. 261, no. 3-4, pp. 534-554, 1998.

[37] H. Milanov and D. A. Shepherd, "The importance of the first relationship: the ongoing influence of initial network on future status," Strategic Management Journal, vol. 34, no. 6, pp. 727-750, 2013.

[38] T. G. Pollock, P. M. Lee, K. Jin, and K. Lashley, "(Un)Tangled," Administrative Science Quarterly, vol. 60, no. 3, pp. 482-517, 2015.

[39] P. Holme, S. Min Park, B. J. Kim, and C. R. Edling, "Korean university life in a network perspective: dynamics of a large affiliation network," Physica A: Statistical Mechanics and Its Applications, vol. 373, pp. 821-830, 2007.

[40] T. Opsahl, F. Agneessens, and J. Skvoretz, "Node centrality in weighted networks: generalizing degree and shortest paths," Social Networks, vol. 32, no. 3, pp. 245-251, 2010. 